\title{
On the necessity of a variety of topics and approaches in articles related to plant breeding. An editorial
}

\author{
Max RIVES
}

Département de Génétique et d'Amélioration des Plantes, I.N.R.A., 11, rue Jean-Nicot, 75007 Paris

\author{
ABSTRACT \\ Plant breeding, \\ Genetics, \\ Objectives \\ and criteria \\ of selection, \\ Theory of \\ selection.
}

\begin{abstract}
The scope and variety of the interests of plant breeders are outlined with reference to the topics of a number of papers proposed for publication in Agronomie.
\end{abstract}

\section{RESUME}

\section{Amélioration \\ des plantes, \\ Génétique, \\ Objectifs \\ et critères \\ de sélection, \\ Théorie de \\ la sélection.}

Nécessité de varier les sujets et les points de vues dans les articles touchant à l'amélioration des plantes

L'auteur indique à propos de quelques articles parus ou à paraître dans Agronomie le domaine d'intérêt des chercheurs en amélioration des plantes et sa variété.
Plant breeding is an art. But it draws heavily upon the knowledge accumulated in a number of sciences.

Genetics of course, to which its servants - the plant breeders - understandably claim that they can make and have made many significant contributions.

But the very finality of plant breeding, this urge to arrive at varieties, and varieties that are as widely grown as possible in agriculture, provides a very potent incentive for the plant breeder to use whatever result of whichever science he can as a mean to pursue his goals.

Broadly speaking, the task of those who investigate the ways and means in plant breeding may be divided in the two phases : methodology of selection on one side, and objectives and criteria for selection on the other.

Methodological studies will aim at optimizing the strategies of selection either by improving the planning of the different phases of the genetical set-up of the selection process, or by improving the evaluation of the genotypes under selection by investigating the practice and theory of experimentation.
Work on objectives and criteria on the other hand is primarily aimed at analysing the directions into which the breeder will have to seek an improvement of the crop, in order to assess the relative value of different types of varieties or of traits in varieties, and at identifying characters that are directly or indirectly connected with the objectives, to be used as criteria for culling within the selected populations.

Methodology relies on a combination of quantitative and population genetics which has conveniently if possibly a little emphatically been termed "theory of selection». It should include a good deal of work on optimizing the experimental set-up of the genetic material throughout the space of the experimental land available and the time of cycles and generations of selection, as well as the study of how to cope with the genotype $x$ environment interactions in selection.

As a discipline it brings a truly scientific facet to the occupation of the plant breeder who spares part of his working time to think and conceive. 
The pursuit of criteria could well remain in the shallow waters of empirical correlations between traits which are the routine reflex of any plant breeder when faced with any objective. However it also may acquire a much more scientific flavor as soon as the breeder starts seeking experimental explanations to the correlations he has found.

A number of papers that have been or will be published in this or other issues of "Agronomie " are good illustrations of this last point.

Work done by I.N.R.A.'s cereal technologists on the gliadins of bread wheat first led to an electrophoretic taxonomic key of the bread wheat varieties on the french catalogue.

Then an investigation on the gliadin electrophoregrams of a series of approximately thirty varieties well-assessed for their bread making value allowed a plant breeder to correlate the presence or absence, and intensity of the gliadin bands with a positive, neutral or negative quality tendency. Furthermore the same breeder has embarked in elucidating the hereditary transmission of the bands. On the basis of these results it will be possible to empirically breed a range of genotypes having the theoretically optimal gliadin electrophoregram and so to check the theory.

The following paper is evidence that our scientists are not satisfied with correlations : they feel the need to understand how and why these correlations are originated from the composition of the proteins gliadins. That is the reason why a paper on the biochemistry of the gliadins, namely their hydrophobicity, has been presented as a paper in plant breeding. The term variety which appears in the title may not be sufficient to justify this claim ; anyone however who is the least familiar with molecular biology will appreciate that everything which relates to the constitution of a protein is directly connected with D N A. i.e genetics, via the traduction and transcription processes.

Another paper may appear as one of these "spraying gardener's" (i.e. doubtfully scientific) article. Indeed the authors did spray young grapevines with chemicals and they do not dare to offer any scientific analysis of their findings. The grapevine breeder who knows that in normal conditions a generation takes five years from seed to seed will appreciate the benefits from these experiments that reduce that time twelve-fold, even though the basic physiological action of the treatment is not known.

Finally, a purely descriptive paper on maize will appear in a later issue. It is merely descriptive but analytic, and apparently highly inspiring for all students of maize performances in connection with its development, since it has been requested from the authors by a number of maize workers.

Variegated is a good plant science word which I think will be found appropriate to describe the full range of topics and approaches that one may expect from the plant breeding part of a journal on agricultural research.

We sincerely hope that variety in this menu will make it as palatable to our colleagues from other parts of plant science as we feel it shall be for our fellow plant breeders.

Reçu le 5 novembre 1980 Accepté le 13 novembre 1980 